Article

\title{
Low-Cost Advanced Hydrogels of Calcium Alginate/Carbon Nanofibers with Enhanced Water Diffusion and Compression Properties
}

\author{
Mar Llorens-Gámez ${ }^{1}$ and Ángel Serrano-Aroca ${ }^{2, *}$ (1) \\ 1 Escuela Técnica Superior de Arquitectura, Universitat Politècnica de València, Camí de Vera s/n, \\ 46022 Valencia, Spain; malloga1@arq.upv.es \\ 2 Facultad de Veterinaria y Ciencias Experimentales, Universidad Católica de Valencia San Vicente Mártir, \\ C/Guillem de Castro 94, 46001 Valencia, Spain \\ * Correspondence: angel.serrano@ucv.es; Tel.: +34-963-63-74-12 (ext. 5256)
}

Received: 28 February 2018; Accepted: 3 April 2018; Published: 4 April 2018

\begin{abstract}
A series of alginate films was synthesised with several calcium chloride cross-linker contents (from 3 to $18 \% w / w)$ with and without a very low amount $(0.1 \% w / w)$ of carbon nanofibers (CNFs) in order to reduce the production costs as much as possible. The results of this study showed a very significant enhancement of liquid water diffusion and mechanical compressive modulus for high calcium chloride contents when this minuscule amount of CNFs is incorporated into calcium alginate hydrogels. These excellent results are attributed to a double cross-linking process, in which calcium cations are capable of cross-linking both alginate chains and CNFs creating a reinforced structure exhibiting ultrafast water diffusion through carbon nanochannels. Thus, these excellent results render these new alginate composites very promising for many bioengineering fields in need of low-cost advanced hydrogels with superior water diffusion and compression properties.
\end{abstract}

Keywords: carbon nanofibers; calcium alginate; composite hydrogels; water diffusion; compression performance; Raman spectroscopy; electron microscopy

\section{Introduction}

Hydrogels are currently employed in a broad range of industrial applications due to their excellent hydrophilic properties [1]. Alginate hydrogels are formed when divalent cations of calcium bridge sodium alginate (SA) polymer chains composed of (1-4)-linked $\beta$-D-mannuronic acid (M) and $\alpha$-L-guluronic acid (G) blocks in different proportions and sequences depending on the source of alginate [2,3]. This cross-linking of the calcium cations occurs through the $\mathrm{G}$ blocks arranged in a block-wise fashion, thus forming the well-known egg-box structure [4]. Alginates have already been approved by the US Food and Drug Administration (FDA) for human use as wound dressing material in biomedical applications [5] due to their non-toxicity, biodegradability, biocompatibility and relative economic cost in comparison with other biopolymers. Therefore, these hydrogels have a wide range of applications in diverse fields, such as water decontamination [6], plastic packaging [7] and bioengineering [8,9]. However, calcium alginate, like most hydrogels, is very brittle [10], and is thus in need of reinforcing strategies to increase exponentially their potential applications. Thus, several methods to enhance the mechanical properties of hydrogels have been developed so far: reinforcement through copolymerisation with hydrophobic monomers [11], interpenetrating polymer networks (IPNs) [12], rise of cross-linking degree [13,14], double cross-linked networks [15], incorporation of nanofibre mats [16], self-sorting [17], plasma-induced polymerisation onto a hydrophobic porous polymer [18-20]. More recently, seemingly even more successful methods include the reinforcement 
of hydrogels by incorporation of carbon materials such as graphene oxide (GO) [21,22] and carbon nanofibers (CNFs) $[23,24]$. However, compared with GO, CNFs have much lower cost and much more electrical conductivity, which can be exploited to fabricate conductive composite materials $[25,26]$. Carbon nanofibers consist of curved graphene layers in the form of quasi one-dimensional (1D) filaments [27], promising to revolutionise several fields in material science [28] due to their excellent chemical, mechanical and electrical properties [29-31]. Thus, these curved graphitic materials are nowadays employed in industrial fields such as polymer additives, gas storage materials, and catalyst supports [32]. Additionally, it has been demonstrated that composites with CNFs are able to promote cardiomyocyte growth [33] and neural regeneration [34] in biomedicine.

Another conductive carbon material, chemically very similar to CNFs, carbon nanotubes (CNTs) have also been used to reinforce hydrogels [35-37]. However, CNFs have lower cost and higher purity level than CNTs, which can result in easier processing of nanocomposites [38].

On the other hand, enhancement of water diffusion in hydrogels is also very desirable in regenerative medicine because it increases cell survival [39] and in bioprocess industries, in which their production depends on the mass transport to the polymer biocatalysts with immobilised cells or enzymes [9]. Since it has been reported that liquid water penetrates graphene-based nanochannels with a diffusion coefficient $4-5$ faster than in the bulk case [40], and water sorption studies in carbon membranes composed of aligned carbon nanotubes [41,42] or GO [43,44] have shown ultrafast diffusion of water through their hydrophobic graphitic nanochannels serving as pores, we assume that a significant enhancement of water diffusion in calcium alginate could be achieved with the incorporation of carbon nanofibers due to its similar chemical structure. However, only a very small amount $(0.1 \% w / w)$ of CNFs was utilised in the synthesis in order to reduce production costs as much as possible and we hypothesize that this low nanofilling can enhance water diffusion and compression performance of alginate hydrogels, depending on the amount of $\mathrm{Ca}^{2+}$ present in the reactive mixture. Furthermore, diverse divalent cations have been shown to be capable of interconnecting or cross-linking nanomaterials such as GO nanosheets [45-47] or CNTs [48], and even chemically modified graphene (CMG) with CNTs [49] through their oxygen functional groups located at the edges and on the basal planes.

Therefore, we assume that 3D networks of CNFs can be cross-linked by metal ion coordination chemistry, as has been reported for the other nanomaterials, inside the alginate matrix when the amount of calcium atoms is high. We believe that when using high calcium chloride contents, the liquid water diffusion and compression properties of calcium alginate hydrogel films must be enhanced because of this double cross-linking process, which can achieve significant reinforcement due to the high degree of connection between the carbon nanofibers inside the cross-linked alginate polymer matrix with carbon nanochannels available for ultrafast water diffusion.

\section{Materials and Methods}

\subsection{Materials}

The sodium alginate (Panreac AppliChem, Darmstadt, Germany) was analysed by ${ }^{1} \mathrm{H}-\mathrm{NMR}$ and Gel Permeation Chromatography (GPC). The results of this characterisation showed an average molar mass of $142.000 \mathrm{~g} / \mathrm{mol}$ and a mannuronate/guluronate ratio of 1.56 . Calcium chloride $(\geq 93.0 \%$, Sigma-Aldrich, Saint Louis, MO, USA) and CNFs (Graphenano, Yecla, Spain) were utilised as received.

\subsection{Synthesis}

A series of alginates with several calcium chloride cross-linker contents $(3,6,12$ or $18 \%$ w/w with respect to the mass of $\mathrm{SA}$ ) and $0.1 \% w / w$ of CNFs were synthesised using a procedure based on the direct mixing method [50]. Thus, 0.25 grams of SA were dissolved into $22 \mathrm{~mL}$ of an aqueous dispersion with $0.001 \% w / v$ of $\mathrm{CNFs}$ and was magnetically stirred for $1 \mathrm{~h}$ at $24 \pm 0.5^{\circ} \mathrm{C}$. The required amount of calcium chloride was separately dissolved in $10 \mathrm{~mL}$ of distilled water and then mixed thoroughly with 
the former CNFs/SA mixture under magnetic stirring. Subsequently, the final solution was cast onto a Petri dish and left in an oven at $37^{\circ} \mathrm{C}$ for $24 \mathrm{~h}$ to form a thin film. Finally, the film was peeled off from the mould and vacuum dry at $60{ }^{\circ} \mathrm{C}$.

Another series of alginates with the same calcium chloride cross-linker contents $(3,6,12$, and $18 \%$ $w / w)$ without CNFs, hereafter referred to as A3, A6, A12 and A18, was prepared following the same procedure, but directly solving only 0.25 grams of SA in $22 \mathrm{~mL}$ of distilled water. The composite hydrogels will be named hereafter by adding -CNFs to the corresponding alginate sample name (A3, A6, A12 or A18).

\subsection{Characterisation}

\subsubsection{Water Sorption and Diffusion}

Water immersion experiments were performed in triplicate to study, in a reproducible manner, water sorption and diffusion at $24 \pm 0.5^{\circ} \mathrm{C}$. Thus, the samples were vacuum-dried at $60{ }^{\circ} \mathrm{C}$ and then immersed in liquid water to be weighted at selected time intervals after drying with filter paper the water drops present on their surfaces.

\subsubsection{Electron Microscopy}

A FEI Tecnai G ${ }^{2}$ F20 (Hillsboro, OR, USA) 200 kV high-resolution transmission electron microscope (HR-TEM) was employed to observe the CNFs dispersed in ethanol placing one drop on a TEM grid with 300 mesh coated in carbon film for five minutes. This electron microscope is equipped with energy-disperse X-ray spectroscopy (EDS) and was used for the elemental analysis of the CNFs at $20 \mathrm{kV}$. The alginate composite hydrogels with $0.1 \% w / w$ of CNFs were observed in a JEM-1010 (JEOL, Tokyo, Japan) $100 \mathrm{kV}$ transmission electron microscope (TEM). Ultrathin sections (60 nm) were prepared using a Leica Ultracut UC6 ultramicrotome (Leica Mikrosysteme GmbH, Wien, Austria) and a Diatome diamond knife (Diatome Ltd., Bienne, Switzerland). The specimens were placed on TEM grids with 300 mesh coated in carbon film.

\subsubsection{Raman Spectroscopy}

A Renishaw inVia (Wotton-under-Edge, UK) confocal micro-Raman spectrometer with an argon ion laser at $633 \mathrm{~nm}$ was utilised to perform Raman scans from 1000 to $3000 \mathrm{~cm}^{-1}$ with $\times 20$ lens at $600 \mathrm{~L} \cdot \mathrm{mm}^{-1}$ grating. Sample preparation consisted of depositing the samples onto a glass substrate.

\subsubsection{Compression Testing}

A texture analyser (Stable Micro System, TA-XT plus, Surrey, UK) with a $50 \mathrm{~N}$ load cell was used to conduct compression testing at $0.06 \mathrm{~mm} \cdot \mathrm{s}^{-1}$ from $0 \%$ to $100 \%$ strain at $24 \pm 0.5{ }^{\circ} \mathrm{C}$. Cylindrical samples $10 \mathrm{~mm}$ in diameter were vacuum-dried at $60^{\circ} \mathrm{C}$ for $24 \mathrm{~h}$ before starting the tests. Six specimens were tested for each kind of sample, and their thickness and diameter were measured with a digital electronic calliper (ACHA, Éibar, Spain).

\section{Results and Discussion}

\subsection{Water Sorption and Diffusion}

Water sorption experiments exhibited a significant reduction of water sorption in the calcium alginate hydrogels with increasing cross-linker content as expected and surprisingly also by the small addition of $0.1 \% w / w$ of CNFs (see Figure 1 ).

The alginate hydrogels with lower cross-linker content, A3 and A6, shows the highest differences between the maximum and the last water uptake (see Figure 1a) due to the fact that they have more uncross-linked alginate chains available for dissolution during the water immersion experiment. The same phenomenon occurs with the A3-CNFs composite sample (see Figure 1b). However, this effect 
is attenuated in the A6-CNFs composite hydrogel, indicating some kind of additional cross-linking. In good agreement with these results, the sample A12-CNFs, which possess higher cross-linker content, exhibits almost no difference between the maximum and the last water uptake in comparison to A12. Furthermore, the pronounced reduction of equilibrium water sorption observed in A18-CNFs in comparison with A18 is remarkable, and reinforces the hypothesis of much higher cross-linking occurring in these composite samples with $0.1 \% w / w$ of CNFs.

According to the Fick's law, water diffusion in hydrogels can be analysed with Equation (1).

$$
\frac{\Delta m_{1, t}}{\Delta m_{1, \infty}} \approx 4\left(\frac{D t}{\pi \cdot l^{2}}\right)^{\frac{1}{2}}
$$

where $\Delta m_{1, t}$ and $\Delta m_{1, \infty}$ are the weight increments at time $t$ and at equilibrium, $l$ is the sample thickness and $D$ the diffusion coefficient. The maximum water contents of Figure 1 were taken as equilibrium values to calculate $\Delta m_{1, \infty}$. The representation of all the $\Delta m_{1, t} / \Delta m_{1, \infty}$ vs. $t^{1 / 2} / l$ plots showed a non-Fickian sorption mechanism [51] in these alginate hydrogels with and without CNFs, which is in good agreement with earlier studies carried out with liquid and vapour water in alginate-based hydrogels [52-55] and in alginate composites hydrogels with other carbon materials [21,56]. However, an apparent diffusion coefficient can be determining by linear regression fitting of Equation (1) for low values of time $t$ or $\Delta m_{1, t} / \Delta m_{1, \infty}<0.5$ to compare liquid water diffusion behaviour in all these similar polymeric systems.

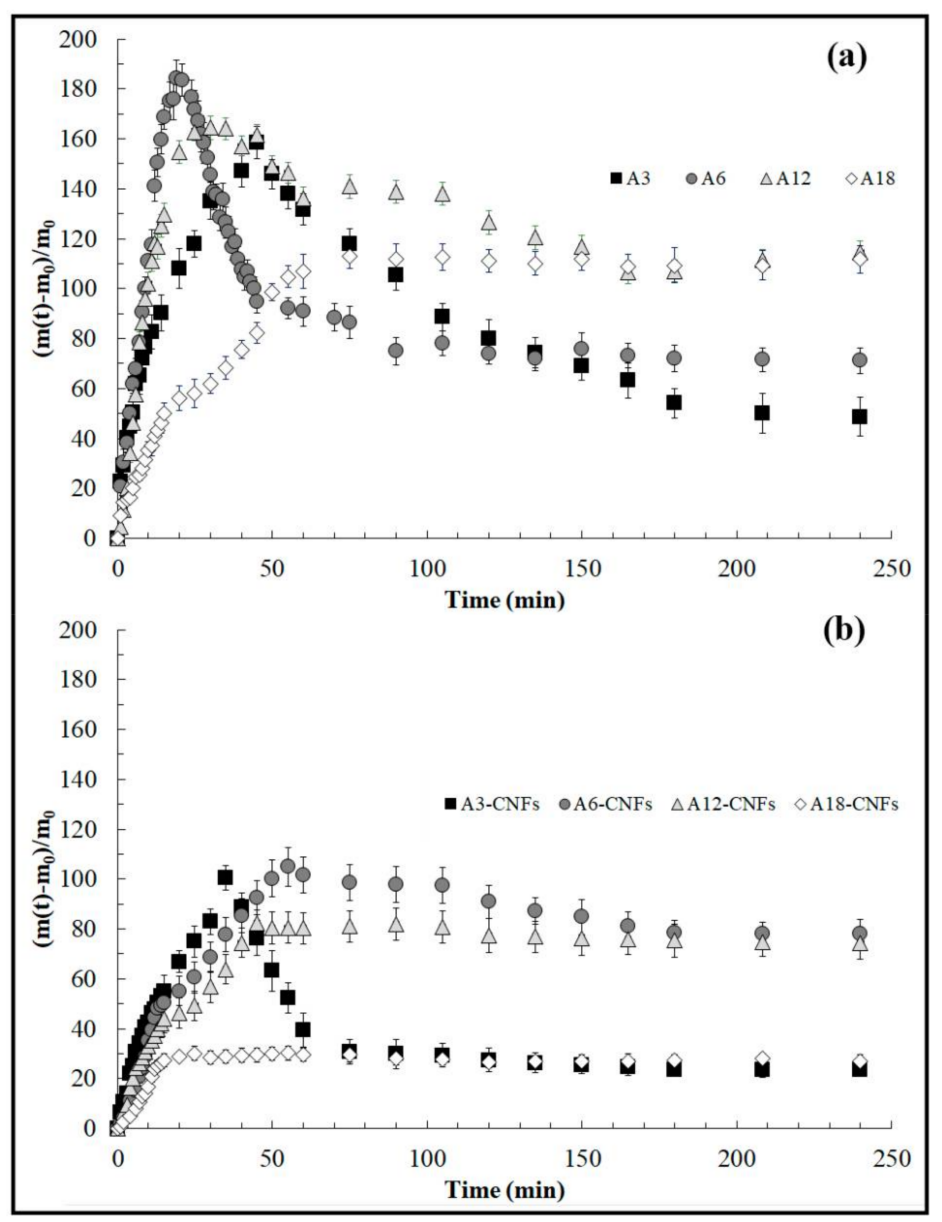

Figure 1. Water contents (grams of absorbed water per grams of dry sample) at $24 \pm 0.5^{\circ} \mathrm{C}$ represented as mean \pm standard deviation for alginate hydrogels synthesised with several calcium chloride contents (a) and with also the addition of $0.1 \% w / w$ of CNFs (b). 
The results of this study showed a significant enhancement of water diffusion in calcium alginate composite hydrogels with $0.1 \% w / w$ of CNFs as compared with the corresponding alginate hydrogels with a similar cross-linker content (see Figure 2). However, this enhancement of water diffusion is attenuated for the lowest cross-linker content. The increase of cross-linker content also produced a significant increase of the water diffusion coefficient probably due to fact that cross-linking between L-guluronic acid $(G)$ blocks must form some kind of discontinuities in the dry state through which water can penetrate faster.

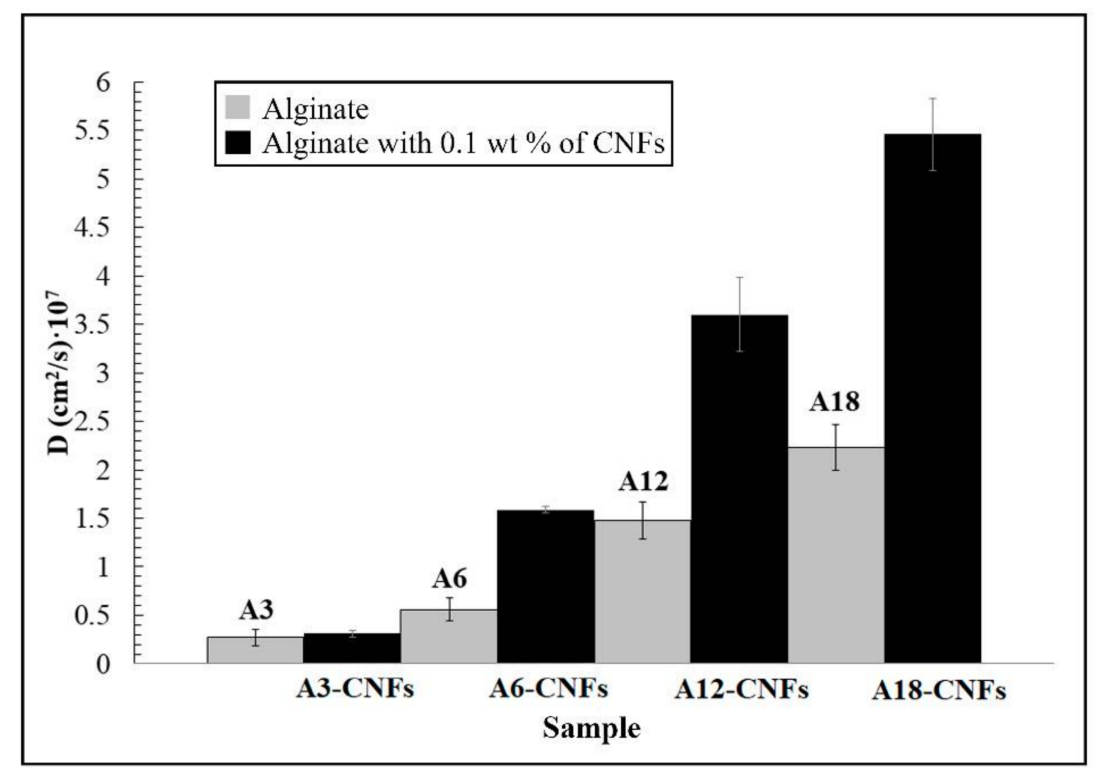

Figure 2. Apparent diffusion coefficients $(D)$ of liquid water in the alginate hydrogels (grey columns) and in the composite alginate hydrogels with $0.1 \% w / w$ of CNFs (black columns) with the indicated cross-linker contents $(3,6,12$ and $18 \% w / w)$. Data are represented as mean \pm standard deviation.

\subsection{Electron Microscopy and Raman Spectroscopy}

The CNFs employed in this study exhibit a morphology of carbon nanofibres with irregular diameters of approximately $10-150 \mathrm{~nm}$ and lengths varying from a few $\mathrm{nm}$ to some $\mu \mathrm{m}$ (see Figure $3 \mathrm{a}, \mathrm{b}$ ).

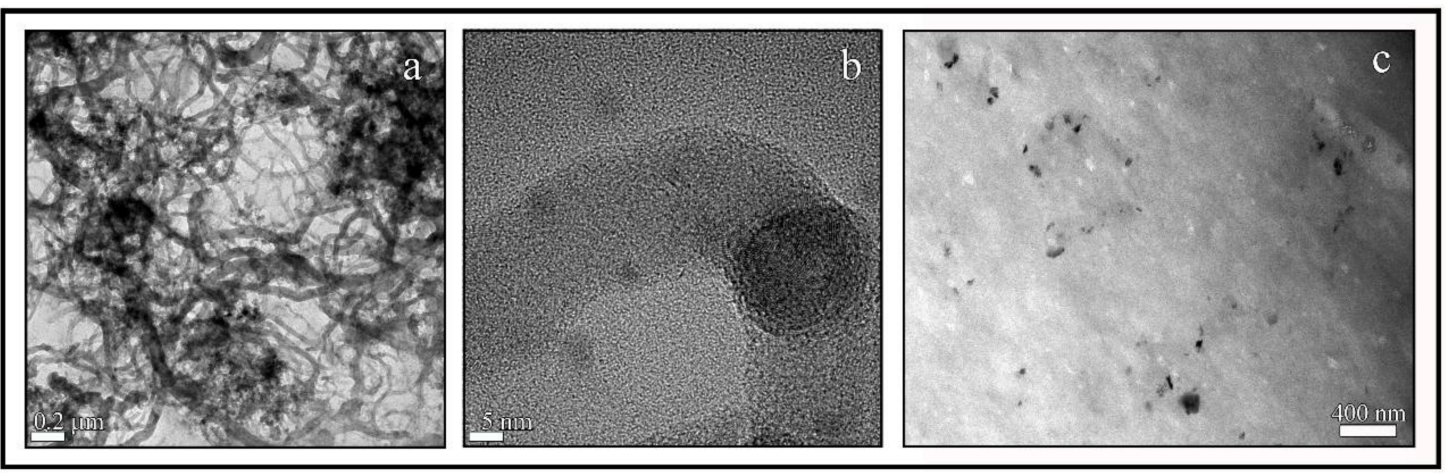

Figure 3. HR-TEM of the CNFs at two magnifications $(\mathbf{a}, \mathbf{b})$ and TEM of A18-CNFs (c).

It is of note that some black spots are present in the HR-TEM micrograph (Figure 3a). Thus, in order to confirm that these spots are only carbon atoms, the atom-atom length was measured in these black points, and the results showed an atom-atom distance of $3.42 \AA$, which corresponds to that of the van der Waals radius of carbon [57]. Furthermore, the EDS analysis supported these results because it showed that the elementary composition of CNFs is composed mostly of carbon atoms and a low \% 
$w / w$ of oxygen atoms (Figure 4). Figure $3 \mathrm{c}$ shows the morphology of the A18-CNFs composite hydrogel composed of alginate (light phase) and carbon nanofibers (dark phase) randomly distributed. It is remarkable that only the large CNFs or cross-linked CNF networks can be appreciated by electron microscopy because they are embedded in the alginate polymer matrix. The TEM morphology of this sample is not very different from those of the other composite hydrogels synthesised with less cross-linker content (images not shown). These connected structures of carbon nanofibers do not allow the A18-CNFs sample to close all of its porosity in the drying process, and some nanochannels are formed in some parts of the sample (see the dark phase of Figure 3c), similar to that which we have recently reported occurs with cross-linked graphene oxide nanosheets in alginate [21]. Thus, water can penetrate very fast through carbon nanochannels [58], increasing the water diffusion coefficient (Figure 2). However, it is much more difficult for water to diffuse in sample A18, because it is non-porous in the dry state.

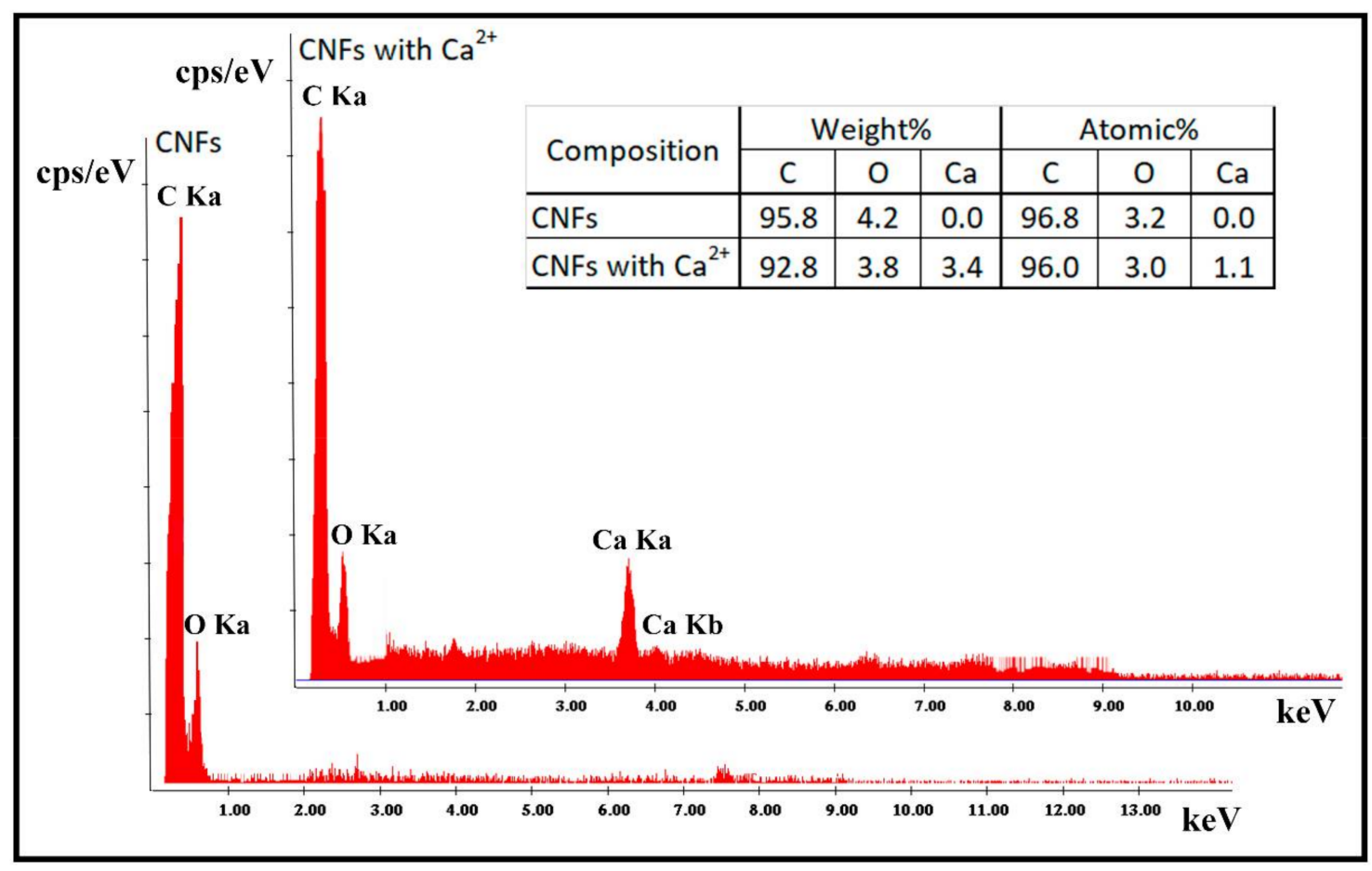

Figure 4. Elementary composition of the carbon nanofibers with and without cross-linking with $\mathrm{Ca}^{2+}$ measured by EDS at $20 \mathrm{kV}$.

In order to ensure that there is a chemical coordination reaction between divalent calcium cations and carbon nanofibers, EDS analysis (Figure 4) and Raman spectroscopy (Figure 5) was performed after dispersing CNF powder in distilled water and subsequent mixing with a $10 \% w / v$ calcium chloride solution with continuous magnetic stirring at $37{ }^{\circ} \mathrm{C}$ following the same procedure described in [45] for graphene oxide nanosheets. Thus, Figure 4 shows that the carbon nanofibers after cross-linking with calcium chloride present an elementary composition with 3.4 weight $\%$ or 1.1 atomic $\%$ of calcium atoms, which is in good agreement with our hypothesis that 3D networks of CNFs can be cross-linked by metal ion coordination chemistry, as has been reported for other nanomaterials also possessing oxygen-containing functional groups [45-49].

Raman spectroscopy is commonly utilised to obtain structural information about defects and ordered/disordered of carbon nanomaterials. The Raman spectrum of CNFs exhibits a strong D band at $\sim 1350 \mathrm{~cm}^{-1}$ and a broad $\mathrm{G}$ band at $\sim 1580 \mathrm{~cm}^{-1}$ [59]. The $\mathrm{D}$ band is attributed to a disordered band due to structural defects, edge effects and dangling $\mathrm{sp}^{2}$ carbon bonds breaking symmetry. The defect/disordered carbon structure is usually measured with the D band/G band intensity ratio 
$\left(I_{\mathrm{D}} / I_{\mathrm{G}}\right)[60,61]$. Thus, Figure 5 shows that after the cross-linking reaction of CNFs with divalent cations of $\mathrm{Ca}^{2+}$, the $I_{\mathrm{D}} / I_{\mathrm{G}}$ ratio decreases from 1471 to 1271 confirming a significant increase of order of the carbon structures due the cross-linking obtained with the calcium cations by coordination chemistry. In addition, the increase of intensity of the 2D band at $2690 \mathrm{~cm}^{-1}$, supports these results, demonstrating higher degrees of order [59] achieved after the coordination reaction.

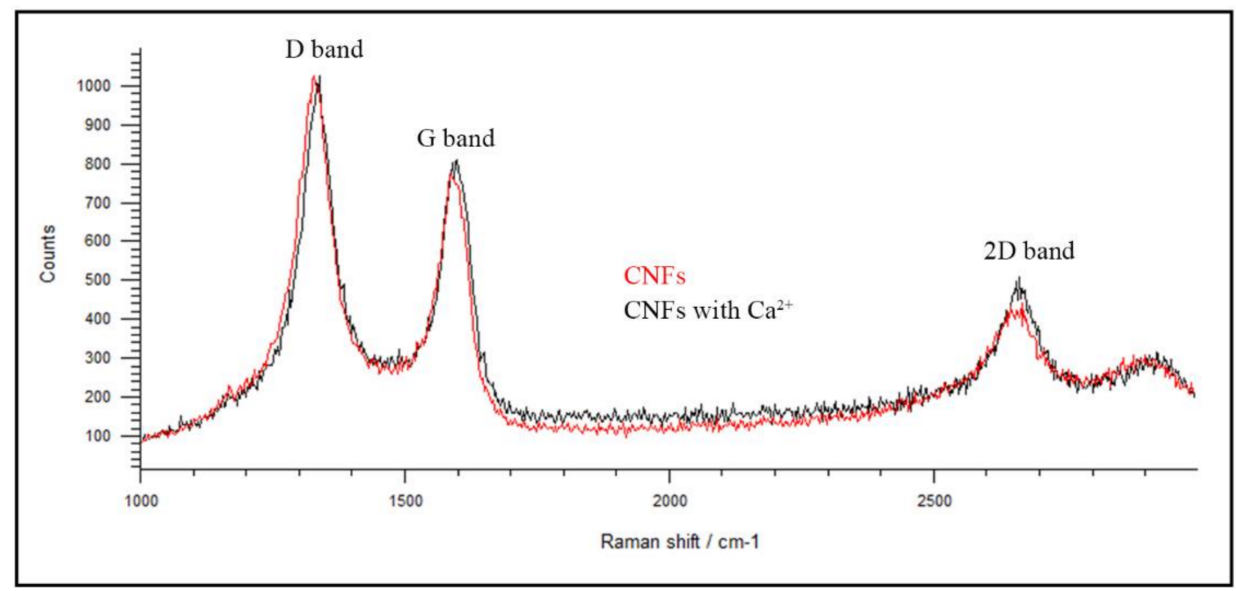

Figure 5. Raman spectra of CNFs and CNFs cross-linked with calcium cations.

\subsection{Compression Performance}

The effect of the addition of $0.1 \% w / w$ of CNFs into the alginate polymer hydrogels became more and more pronounced with increased weight percentage of calcium chloride (see Figure 6). Hence, the composite sample A18-CNFs exhibited a compressive modulus almost 3 times higher than that of sample A18. This excellent result can also be attributed to the formation of reinforcing cross-linked CNFs networks by coordination chemistry with divalent cations of $\mathrm{Ca}^{2+}$ inside the cross-linked alginate polymer structure. For this reason, the alginate composite synthesised with lower amounts of calcium chloride such as A3-CNFs showed lower reinforcement with respect to A3 because there was a smaller number of divalent cations to connect alginate chains and carbon nanofibers.

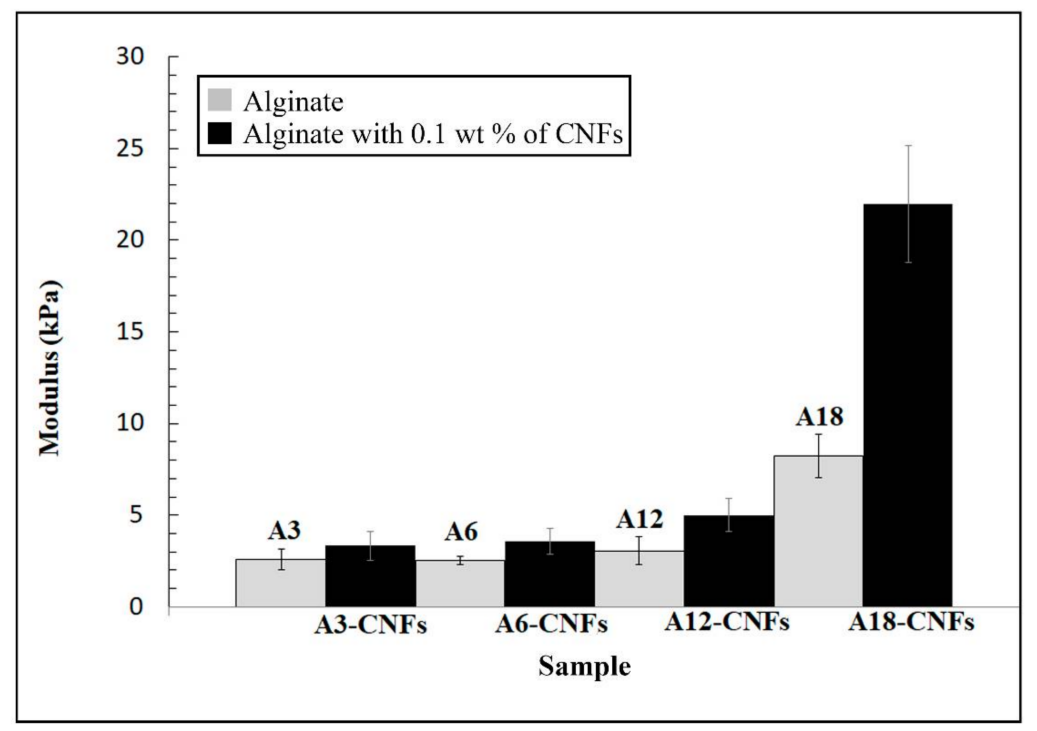

Figure 6. Mechanical compressive modulus (mean \pm standard deviation) of alginate hydrogels (grey columns) and alginate composite hydrogels with $0.1 \% w / w$ of CNFs (black columns) cross-linked with increasing amounts of calcium chloride $(3,6,12$ and $18 \% w / w)$. 
The reinforcement of calcium alginate achieved with the use of CNFs in this study is lower than that obtained in a previous study utilising the same amount of GO and calcium chloride [21]. This fact occurs because GO possess more oxygen functional groups than CNFs, and thus more cross-linking points. In that study, the enhancement of water diffusion achieved with the addition of $0.1 \% w / w$ of GO was also higher than that obtained here with $0.1 \% w / w$ of CNFs due to the presence of more carbon nanochannels in the dry state produced by the higher cross-linking between GO nanosheets.

Nevertheless, CNFs have much lower cost than GO (e.g., approximately 21 times more economical than GO when obtained from Sigma-Aldrich) and have attracted great interest in the field of regeneration medicine due to their excellent mechanical, magnetic and electrical properties [34], which renders these advanced composite materials very promising for certain biomedical and industrial applications in need of low-cost hydrogels with these required physical properties.

\section{Conclusions}

The effect of cross-linker content on water diffusion and compression performance was studied in carbon nanofibers/calcium alginate composite hydrogels synthesised with a very low amount of nanomaterial $(0.1 \% w / w)$. The results of this study showed that a minuscule amount of CNFs can significantly enhance liquid water diffusion and compression in calcium alginate hydrogels due to the formation of connected CNFs networks by coordination chemistry inside the cross-linked alginate polymer matrix. This enhancement of properties increases with increasing cross-linker content due to the formation of cross-linked carbon nanochannels able to improve water diffusion and mechanical compression at the same time. These achievements demonstrate the potential utilisation of these new alginate composite hydrogels in many industrial applications currently in need of low-cost advanced hydrogels with enhanced compression and water diffusion properties.

Acknowledgments: The authors would like to acknowledge the Universidad Católica de Valencia San Vicente Mártir and the Ministry of Economy, Industry and Competitiveness for the financial support of this work through the 2018-231-001UCV and MAT2015-69315-C3-1-R grants respectively.

Author Contributions: Ángel Serrano-Aroca conceived the idea of this work, designed the synthesis and characterisation experiments, performed the electronic microscopy and Raman spectroscopy, analysed and discussed the data results and prepared the manuscript text and figures. Mar Llorens-Gámez performed the synthesis of the materials, compression testing, water sorption experiments, and contributed to the manuscript figures.

Conflicts of Interest: The authors declare no conflict of interest.

\section{References}

1. Ahmed, E.M. Hydrogel: Preparation, characterization, and applications: A review. J. Adv. Res. 2015, 6, 105-121. [CrossRef] [PubMed]

2. Kaplan, D.L. (Ed.) Biopolymers from Renewable Resources; Springer: Berlin/Heidelberg, Germany, 1998.

3. Vauchel, P.; Kaas, R.; Arhaliass, A.; Baron, R.; Legrand, J. A New Process for Extracting Alginates from Laminaria digitata: Reactive Extrusion. Food Bioprocess Technol. 2008, 1, 297-300. [CrossRef]

4. Grant, G.T.; Morris, E.R.; Rees, D.A.; Smith, P.J.C.; Thom, D. Biological interactions between polysaccharides and divalent cations: The egg-box model. FEBS Lett. 1973, 32, 195-198. [CrossRef]

5. Godbey, W.T.; Atala, A. In vitro systems for tissue engineering. Ann. N. Y. Acad. Sci. 2002, 961, 10-26. [CrossRef] [PubMed]

6. Draget, K.; Skjakbrak, G.; Smidsrod, O. Alginic acid gels: The effect of alginate chemical composition and molecular weight. Carbohydr. Polym. 1994, 25, 31-38. [CrossRef]

7. Zactiti, E.M.; Kieckbusch, T.G. Release of potassium sorbate from active films of sodium alginate crosslinked with calcium chloride. Packag. Technol. Sci. 2009, 22, 349-358. [CrossRef]

8. Ratner, B.D.; Hoffman, A.S.; Schoen, F.J.; Lemons, J.E. Biomaterials Science: An Introduction to Materials in Medicine; Academic Press: Toronto, ON, Canada, 2012; ISBN 008087780X.

9. Doran, P.M. Bioprocess Engineering Principles; Academic Press: Oxford, UK, 2013. 
10. Sun, J.Y.; Zhao, X.; Illeperuma, W.R.K.; Chaudhuri, O.; Oh, K.H.; Mooney, D.J.; Vlassak, J.J.; Suo, Z. Highly stretchable and tough hydrogels. Nature 2012, 489, 133-136. [CrossRef] [PubMed]

11. Pérez Olmedilla, M.; Garcia-Giralt, N.; Pradas, M.M.; Ruiz, P.B.; Gómez Ribelles, J.L.; Palou, E.C.; García, J.C.M. Response of human chondrocytes to a non-uniform distribution of hydrophilic domains on poly(ethyl acrylate-co-hydroxyethyl methacrylate) copolymers. Biomaterials 2006, 27, 1003-1012. [CrossRef] [PubMed]

12. Li, P.; Dou, X.-Q.; Feng, C.-L.; Zhang, D. Mechanical reinforcement of $\mathrm{C}_{2}$-phenyl-derived hydrogels for controlled cell adhesion. Soft Matter 2013, 9, 3750-3757. [CrossRef]

13. Monleón-Pradas, M.; Gómez-Ribelles, J.L.; Serrano-Aroca, Á.; Gallego-Ferrer, G.; Suay-Antón, J.; Pissis, P. Interaction between water and polymer chains in poly(hydroxyethyl acrylate) hydrogels. Colloid Polym. Sci. 2001, 279, 323-330. [CrossRef]

14. Serrano-Aroca, Á.; Monleón-Pradas, M.; Gómez-Ribelles, J.L. Effect of crosslinking on porous poly(methyl methacrylate) produced by phase separation. Colloid Polym. Sci. 2008, 286, 209-216. [CrossRef]

15. Zhao, W.; Han, Z.; Ma, L.; Sun, S.; Zhao, C. Highly hemo-compatible, mechanically strong, and conductive dual cross-linked polymer hydrogels. J. Mater. Chem. B 2016, 4, 8016-8024. [CrossRef]

16. Khoushabi, A.; Schmocker, A.; Pioletti, D.P.; Moser, C.; Schizas, C.; Manson, J.A.; Bourban, P.E. Photo-polymerization, swelling and mechanical properties of cellulose fibre reinforced poly(ethylene glycol) hydrogels. Compos. Sci. Technol. 2015, 119, 93-99. [CrossRef]

17. Koenigs, M.M.E.; Pal, A.; Mortazavi, H.; Pawar, G.M.; Storm, C.; Sijbesma, R.P. Tuning cross-link density in a physical hydrogel by supramolecular self-sorting. Macromolecules 2014, 47, 2712-2717. [CrossRef]

18. Serrano-Aroca, Á.; Gómez-Ribelles, J.L.; Monleón-Pradas, M.; Vidaurre-Garayo, A.; Suay-Antón, J. Characterisation of macroporous poly(methyl methacrylate) coated with plasma-polymerised poly(2-hydroxyethyl acrylate). Eur. Polym. J. 2007, 43, 4552-4564. [CrossRef]

19. Serrano-Aroca, Á.; Monleón-Pradas, M.; Gómez-Ribelles, J.L.; Rault, J. Thermal analysis of water in reinforced plasma-polymerised poly(2-hydroxyethyl acrylate) hydrogels. Eur. Polym. J. 2015, 72, 523-534. [CrossRef]

20. Serrano-Aroca, Á.; Monleón-Pradas, M.; Gómez-Ribelles, J.L. Plasma-induced polymerisation of hydrophilic coatings onto macroporous hydrophobic scaffolds. Polymer 2007, 48, 2071-2078. [CrossRef]

21. Serrano-Aroca, Á.; Ruiz-Pividal, J.F.; Llorens-Gámez, M. Enhancement of water diffusion and compression performance of crosslinked alginate with a minuscule amount of graphene oxide. Sci. Rep. 2017, 7, 11684. [CrossRef] [PubMed]

22. Sánchez-Correa, F.; Vidaurre-Agut, C.; Serrano-Aroca, A.; Campillo-Fernández, A.J. Poly(2-hydroxyethyl acrylate) hydrogels reinforced with graphene oxide: Remarkable improvement of water diffusion and mechanical properties. J. Appl. Polym. Sci. 2018, 135, 46158. [CrossRef]

23. Wu, X.L.; Wen, T.; Guo, H.L.; Yang, S.; Wang, X.; Xu, A.W. Biomass-derived sponge-like carbonaceous hydrogels and aerogels for supercapacitors. ACS Nano 2013, 7, 3589-3597. [CrossRef] [PubMed]

24. Ahadian, S.; Ramón-Azcón, J.; Estili, M.; Liang, X.; Ostrovidov, S.; Shiku, H.; Ramalingam, M.; Nakajima, K.; Sakka, Y.; Bae, H.; et al. Hybrid hydrogels containing vertically aligned carbon nanotubes with anisotropic electrical conductivity for muscle myofiber fabrication. Sci. Rep. 2014, 4, 4271. [CrossRef] [PubMed]

25. Stout, D.A.; Basu, B.; Webster, T.J. Poly(lactic-co-glycolic acid): Carbon nanofiber composites for myocardial tissue engineering applications. Acta Biomater. 2011, 7, 3101-3112. [CrossRef] [PubMed]

26. Morales, G.; Barrena, M.I.; de Salazar, J.M.G.; Merino, C.; Rodríguez, D. Conductive CNF-reinforced hybrid composites by injection moulding. Compos. Struct. 2010, 92, 1416-1422. [CrossRef]

27. Baker, R.T.K. Catalytic growth of carbon filaments. Carbon 1989, 27, 315-323. [CrossRef]

28. Hammel, E.; Tang, X.; Trampert, M.; Schmitt, T.; Mauthner, K.; Eder, A.; Pötschke, P. Carbon nanofibers for composite applications. Carbon 2004, 42, 1153-1158. [CrossRef]

29. Zhang, L.; Aboagye, A.; Kelkar, A.; Lai, C.; Fong, H. A review: Carbon nanofibers from electrospun polyacrylonitrile and their applications. J. Mater. Sci. 2014, 49, 463-480. [CrossRef]

30. Morgan, P. Carbon Fibers and Their Composites, 1st ed.; Taylor \& Francis: Boca Raton, FL, USA, 2005; ISBN 9780824709839.

31. Gardea, F.; Naraghi, M.; Lagoudas, D. Effect of thermal interface on heat flow in carbon nanofiber composites. ACS Appl. Mater. Interfaces 2014, 6, 1061-1072. [CrossRef] [PubMed]

32. De Jong, K.P.; Geus, J.W. Carbon Nanofibers: Catalytic Synthesis and Applications. Catal. Rev. 2000, 42, 481-510. [CrossRef] 
33. Stout, D.A.; Yoo, J.; Santiago-Miranda, A.N.; Webster, T.J. Mechanisms of greater cardiomyocyte functions on conductive nanoengineered composites for cardiovascular applications. Int. J. Nanomed. 2012, 7, 5653-5669. [CrossRef]

34. Tran, P.A.; Zhang, L.; Webster, T.J. Carbon nanofibers and carbon nanotubes in regenerative medicine. Adv. Drug Deliv. Rev. 2009, 61, 1097-1114. [CrossRef] [PubMed]

35. Wu, S.; Duan, B.; Lu, A.; Wang, Y.; Ye, Q.; Zhang, L. Biocompatible chitin/carbon nanotubes composite hydrogels as neuronal growth substrates. Carbohydr. Polym. 2017, 174, 830-840. [CrossRef] [PubMed]

36. Shin, J.; Choi, E.J.; Cho, J.H.; Cho, A.-N.; Jin, Y.; Yang, K.; Song, C.; Cho, S.-W. Three-Dimensional Electroconductive Hyaluronic Acid Hydrogels Incorporated with Carbon Nanotubes and Polypyrrole by Catechol-Mediated Dispersion Enhance Neurogenesis of Human Neural Stem Cells. Biomacromolecules 2017, 18. [CrossRef] [PubMed]

37. Song, Y.; Sun, Z.; Xu, L.; Shao, Z. Preparation and characterization of highly aligned carbon nanotubes/polyacrylonitrile composite nanofibers. Polymers 2017, 9, 1. [CrossRef]

38. Wood, W.; Li, B.; Zhong, W.-H. Influence of Phase Morphology on the Sliding Wear of Polyethylene Blends Filled with Carbon Nanofibers. Polym. Eng. Sci. 2010, 50, 613-623. [CrossRef]

39. Van Blitterswijk, C.; De Boer, J. Tissue Engineering; Academic Press: Oxford, UK, 2014.

40. Sun, P.; Liu, H.; Wang, K.; Zhong, M.; Wu, D.; Zhu, H. Ultrafast liquid water transport through graphene-based nanochannels measured by isotope labelling. Chem. Commun. 2015, 51, 3251-3254. [CrossRef] [PubMed]

41. Holt, J.K. Fast Mass Transport through Sub-2-Nanometer Carbon Nanotubes. Science 2006, 312, $1034-1037$. [CrossRef] [PubMed]

42. Majumder, M.; Chopra, N.; Andrews, R.; Hinds, B.J. Nanoscale hydrodynamics: Enhanced flow in carbon nanotubes. Nature 2005, 438, 44. [CrossRef] [PubMed]

43. Boukhvalov, D.W.; Katsnelson, M.I.; Son, Y.W. Origin of anomalous water permeation through graphene oxide membrane. Nano Lett. 2013, 13, 3930-3935. [CrossRef] [PubMed]

44. Nair, R.R.; Wu, H.A.; Jayaram, P.N.; Grigorieva, I.V.; Geim, A.K. Unimpeded Permeation of Water through Helium-Leak-Tight Graphene-Based Membranes. Science 2012, 335, 442-444. [CrossRef] [PubMed]

45. Serrano-Aroca, Á.; Deb, S. Synthesis of irregular graphene oxide tubes using green chemistry and their potential use as reinforcement materials for biomedical applications. PLoS ONE 2017, 12, e0185235. [CrossRef] [PubMed]

46. Park, S.; Lee, K.-S.; Bozoklu, G.; Cai, W.; Nguyen, S.T.; Ruoff, R.S. Graphene oxide papers modified by divalent ions-enhancing mechanical properties via chemical cross-linking. ACS Nano 2008, 2, 572-578. [CrossRef] [PubMed]

47. Bai, H.; Li, C.; Wang, X.; Shi, G. On the Gelation of Graphene Oxide. J. Phys. Chem. C 2011, 115, 5545-5551. [CrossRef]

48. Park, M.; Kim, B.H.; Kim, S.; Han, D.S.; Kim, G.; Lee, K.R. Improved binding between copper and carbon nanotubes in a composite using oxygen-containing functional groups. Carbon 2011, 49, 811-818. [CrossRef]

49. Liu, Y.T.; Feng, Q.P.; Xie, X.M.; Ye, X.Y. The production of flexible and transparent conductive films of carbon nanotube/graphene networks coordinated by divalent metal ( $\mathrm{Cu}, \mathrm{Ca}$ or $\mathrm{Mg}$ ) ions. Carbon 2011, 49, 3371-3375. [CrossRef]

50. Rhim, J.W. Physical and mechanical properties of water resistant sodium alginate films. LWT Food Sci. Technol. 2004, 37, 323-330. [CrossRef]

51. Crank, J. The Mathematics of Diffusion, 2nd ed.; Oxford University Press: Bristol, UK, 1975.

52. Şolpan, D.; Torun, M. Synthesis and characterization of sodium alginate/acrylamide semi-interpenetrating polymer networks. J. Appl. Polym. Sci. 2006, 100, 335-342. [CrossRef]

53. Dhanapal, V.; Subramanian, K. Recycling of reactive dye using semi-interpenetrating polymer network from sodium alginate and isopropyl acrylamide. J. Appl. Polym. Sci. 2014, 131. [CrossRef]

54. Andreopoulos, A.G. Diffusion characteristics of alginate membranes. Biomaterials 1987, 8, 397-400. [CrossRef]

55. Hirai, A.; Odani, H. Sorption and transport of water vapor in alginic acid, sodium alginate, and alginate-cobalt complex films. J. Polym. Sci. Part B 1994, 32, 2329-2337. [CrossRef]

56. Vilcinskas, K.; Zlopasa, J.; Jansen, K.M.B.; Mulder, F.M.; Picken, S.J.; Koper, G.J.M. Water Sorption and Diffusion in (Reduced) Graphene Oxide-Alginate Biopolymer Nanocomposites. Macromol. Mater. Eng. 2016, 301, 1049-1063. [CrossRef] 
57. Zefirov, Y.V.; Zorky, P.M. New applications of van der Waals radii in chemistry. Russ. Chem. Rev. 1995, 64, 415-428. [CrossRef]

58. Xie, Q.; Alibakhshi, M.A.; Jiao, S.; Xu, Z.; Hempel, M.; Kong, J.; Park, H.G.; Duan, C. Fast water transport in graphene nanofluidic channels. Nat. Nanotechnol. 2018, 13, 238-245. [CrossRef] [PubMed]

59. Liu, Y.; Pan, C.; Wang, J. Raman spectra of carbon nanotubes and nanofibers prepared by ethanol flames. J. Mater. Sci. 2004, 39, 1091-1094. [CrossRef]

60. Ferrari, A.C.; Robertson, J. Interpretation of Raman spectra of disordered and amorphous carbon. Phys. Rev. B 2000, 61, 14095-14107. [CrossRef]

61. Cançado, L.G.; Jorio, A.; Ferreira, E.H.M.; Stavale, F.; Achete, C.A.; Capaz, R.B.; Moutinho, M.V.O.; Lombardo, A.; Kulmala, T.S.; Ferrari, A.C. Quantifying defects in graphene via Raman spectroscopy at different excitation energies. Nano Lett. 2011, 11, 3190-3196. [CrossRef] [PubMed]

C 2018 by the authors. Licensee MDPI, Basel, Switzerland. This article is an open access article distributed under the terms and conditions of the Creative Commons Attribution (CC BY) license (http:/ / creativecommons.org/licenses/by/4.0/). 